O trabalho de prevenção com crianças na idade de aprender o controle esfincteriano permite, às vezes, observar, por ocasião desta etapa, um despertar agudo de angústias primitivas de ressecamento $e$ de liquefação que entravam o investimento normal desta função. Propomo-nos, neste artigo, dar um testemunho disto, com duas vinhetas clínicas, que ressaltam o quanto as noçōes teóricas de angústia de morte por escoamento e liquefação, descritas no campo da clínica do autismo, esclarecem, igualmente, esta etapa da infância. Aprendizagem do controle esfincteriano; angústia de ressecamento; vivências intra-uterina e peri-natais

THE AWAKENING UP OF RESECTION ANXIETIES DURING SPHINCTER CONTROL LEARNING

The prevention work with children at the age of learning sphincter control leads to the observation of an awakening up of primitive anxieties associated to resection and to liquefaction which stops the normal investment of this function.. We show, in this article, two pieces from two clinical stories, that clear up some theoretical concepts associated to the clinic of the autism.

Sphincter control learning; flowage anxiety;resection. anxiety;intrauterine life and before birth

\section{A RUPTURA DA \\ BOLSA NO PARTO \\ OU O DESPERTAR \\ DAS ANGÚSTIAS DE \\ RESSECAMENTO \\ DURANTE A \\ APRENDIZAGEM \\ DO CONTROLE \\ ESFINCTERIANO}

$\bigwedge$ etapa da aprendizagem do controle esfincteriano é, freqüentemente, relacionada à noção do "estágio anal" como Freud o definiu, ou seja, relacionada com um hiperinvestimento desta zona enquanto lugar de trocas relacionais possíveis, permitindo investir e explorar a possibilidade de agradar ou não ao outro, dar, assim como recusar, guardando para si, acumular, desfazer-se de alguma coisa, reter. Os excrementos são, para todo neurótico, simbólicos de uma parte do corpo que pode ir

Psicanalista, professora de Psicopatologia Clínica na Universidade Paul Valéry-Montpellier III.

- Doutora em Psicopatologia Clínica na Universidade de Paris Vil e psicoterapeuta. 
embora, de acordo com a equação descrita por Freud: excrementos-presentes-ouro-bebê-pênis.

É interessante observar, na prática com criança pequena, o quanto certas fragilidades narcísicas e angústias precoces podem interferir e perturbar esta etapa da aprendizagem do controle esfincteriano.

Desejamos, particularmente, chamar a atenção para o despertar de angústias de liquefação e de morte por ressecamento, quer dizer, angústias arcaicas ligadas ao estágio fetal e ao parto, que podem ocorrer de maneira violenta, no momento da aprendizagem do controle esfincteriano, isto é, quando o trabalho de investimento das funções de evacuação excrementícia se instala. Em algumas crianças, vemos emergir uma fase de ansiedade, até mesmo de angústia aguda, cuja especificidade apresentaremos com duas vinhetas clínicas.

Mostraremos agora como, clinicamente, a etapa da aprendizagem do controle esfincteriano pode despertar, em algumas crianças, angústias precoces, que entravam, consideravelmente, esta "mudança".

\section{O CASO DE ADRIANO}

Lembraremos o que podem ser as angústias de liquefação e de escoamento sem fim retomando, sucintamente, as idéias de F. Tustin sobre "os terrores primitivos" que ela particularmente explicitou, a partir da clínica do autismo. F. Tustin (1989) descreve, de fato, medos fundamentais: de cair, de ser atirado, de desmoronar, de se despedaçar, de transbordar, de se dissolver, de explodir. Ela relaciona isto ao que Bion chama "os terrores sem nome", e às vivências precoces do lactente.

No que diz respeito ao terror de transbordar, ela refere uma paciente para quem transbordar era equivalente a esquecer o pânico e a angústia que resultam destes terrores devidos à impressão de cair em um abismo sem fim, no nada, o que remete a uma falha do continente, à ausência de retorno psíquico fornecido pela mentalização materna.

Essas angústias podem igualmente tomar um outro aspecto: o de uma ameaça de dissolução, isto é, o temor de passar de um estado sólido para um estado líquido, daí um risco de morte por escoamento.

De fato, esses terrores primitivos são vividos pelo sujeito como verdadeiros perigos de morte. A fim de lutar contra essas angústias, a criança pode se enrijecer na perspectiva de se endurecer para evitar o 
escoamento. Assim, G. Haag (1994) relata o caso de uma criança que apresentava, em seu estado autístico, intensas angústias de liquefação e de dessecação contra as quais ela lutava lançando mão de um hiperfechamento do corpo, ao mesmo tempo muscular e visceral. Para F. Tustin, as condutas de fechamento são necessidades defensivas derivadas da "infiltração de condutas de agarramento no âmbito do domínio".

$O$ enrijecimento que serve para fixar as coisas, para imobilizá-las, pode levar a criança a viver as mudanças como catástrofes. É o que nos parece revelar-se no caso de Adriano no nível da retenção das palavras e, em um determinado momento de sua evolução, das fezes.

\section{OS SINTOMAS}

Adriano é uma criança de 4 anos que encontrou dificuldades em obter o controle esfincteriano e que tem problemas de elocução: falta de fluência das palavras e gagueira. Ele não consegue encadear as sílabas umas nas outras. Parece conseguir fazer no penico, ao redor dos 3 anos e 5 meses, depois volta a fazer nas calças, aos 4 anos. Neste momento, se intensificam os problemas de elocução.

O contato com algo úmido e quente em suas calças parece predominante, uma espécie de júbilo que aparece enquanto as fezes ainda estão mornas.

O. Rank analisou na criança pequena, ainda lactente, esta busca, por meio das fezes quentes, do contato com as substâncias corporais da mãe das quais se separou ao nascer, lembrando o contexto uterino. As preocupações compulsivas de Adriano parecem reativar vivências arcaicas anteriores à sua vida extra-uterina.

Ele besunta com fezes seus objetos de pelúcia e manifesta muito prazer, depois, ao vê-los serem lavados, bate palmas quando sua mãe colocaos no jardim e passa o jato de água sobre eles. Com freqüência, se atira embaixo do jato.

Paralelamente à busca efetuada a partir das secreções do corpo, a procura de algo úmido parece ocorrer no ambiente externo.

$\mathrm{Na}$ sessão, ele pede barro e, tendo, várias vezes, conseguido pegar a terra de um pote de planta, mistura esta terra com a água de uma bacia na qual tinha o hábito de afogar, compulsivamente, seus brinquedos, um após o outro. A textura do barro fará amplificar este ritual de "afogamento" dos personagens, cuja cabeça ele mergulha no barro, como um alucinado.

A busca da água é constante: assim que ele vê uma bacia ou poça d'água, joga-se dentro, colocando de preferência a cabeça dentro da água ou mesmo no barro.

Durante esse tipo de atividade, ele parece totalmente fascinado pela água e pelo revestimento úmido das superfícies dos objetos de pelúcia. Parece absorvido por algo fundamental para ele. Não se dirige a ninguém, não espreita o adulto e não brinca com a reação deste último. A água parece exercer sobre ele uma função de "objeto atraidor", confor- 
me o conceito descrito por D. Meltzer, ao mesmo tempo reunindo-o e absorvendo-o; esta ação compulsiva evoca uma vivência traumática não resolvida e constitui um obstáculo quanto à aprendizagem definitiva do controle esfincteriano.

Ele se comunica pouco com as outras crianças da escola, se retrai.

\section{A HISTÓRIA DA CRIANCCA}

A mãe é anorética desde os 18 anos. Teve Adriano aos 28 anos, pensando que não poderia engravidar. Não menstruando, não era necessário tomar pílula, pensava ela. Pesava 35 $\mathrm{kg}$ para uma altura de $1,63 \mathrm{~m}$. As crises de bulimia sucederam-se, dia e noite, aos 19 anos, após a ruptura com um rapaz, quando tinha 16 anos. A avó materna, a quem era muito apegada, adoeceu gravemente alguns meses depois desta ruptura e morreu quando ela tinha 19 anos.

Aos 16 anos, tinha estado grávida durante 2 meses e meio, após relações sexuais com um jovem de 17 anos. Descobrira sua gravidez durante o aborto, provocado por uma queda violenta após choque com uma rocha, quando fazia windsurf. Uma depressão começou aos 18 anos, depois, aos 19 anos, instalaram-se, após retraimento total, crises de bulimia sempre seguidas de vômitos.

Grávida de Adriano, teve de ficar sob perfusão a partir do sexto mês de gravidez. O corpo do bebê descera, e a sua cabeça encontrava-se muito perto do colo, aos 7 meses de gravidez. O parto foi rápido, normal, sem peridural, sem cesariana, apesar do parecer do médico, que diagnosticara parto com cesariana. A criança nasce, hiperagitada, com os olhos arregalados, o que surpreende todo o mundo.

As crises de vômitos foram intensas durante a gravidez, inexoráveis, após cada refeição. As sacudidas repetidas que a criança pode ter sentido dentro do ventre materno provocaram, sem dúvida, a sua descida rápida em direção ao colo.

O meio amniótico foi prejudicado, durante um certo tempo, pela pouca quantidade de substâncias que restavam dentro do corpo, devido aos vômitos repetidos. Podemos pensar que a criança pôde sentir medos de ressecamento dentro do corpo da mãe e que a descida rápida poderia se explicar como um movimento para fugir de um meio aquático insuficiente e perigoso.

A criança suga depois avidamente o seio, reclamando uma nova mamada alguns instantes depois da primeira.

A mãe foi hospitalizada três vezes, dos 23 aos 28 anos. Retomou facilmente alguns quilos, em uma clínica, mas, nos quatro meses seguintes, voltou a emagrecer, voltando ao seu peso inicial.

Quando sua mãe foi para a clínica, Adriano, então com 4 anos, recomeçou a se sujar e a manipular os excrementos com uma evidente satisfação. Espalha as fezes sobre o corpo, as pernas, o ventre, assim como sobre os objetos de pelúcia, como descrevemos anteriormente. 
Adriano vira sua mãe se esvaziar, várias vezes, no vaso sanitário. É provável que ele tenha sido afetado por isto, pois foi surpreendido, várias vezes, ao redor dos 4 anos, com os dedos na boca, para tentar provocar o vômito.

Pode-se pensar que os órgãos de excreção anal substituem a boca e expulsam, como a boca da mãe, devido a uma espécie de confusão psicótica dos orifícios.

Ele parece reviver, com a separação do objeto primário, temores de ressecamento devidos aos primeiros traumas intra-uterinos e também às hospitalizações da mãe. Pede para beber, muito freqüentemente, de maneira compulsiva, parecendo adicto à água (cf. estudos de Anna Freud).

Adriano fica a cargo de seu pai, durante a hospitalização da mãe. Os distúrbios de linguagem durarão muito tempo e aumentarão como se não ocorresse a liquidez requerida para ligar uma sílaba à outra e como se o fluxo salivar se tornasse insuficiente. Queixa-se, com freqüência, de ter a boca seca e, por isto, pede água.

A mãe aprendera com sua avó materna, que vivera muito tempo na Argélia, o hábito de cuidar do corpo por meio de massagens e o transmitira para seu filho, besuntando-o, com freqüência, com creme ou óleo - espécie de rituais em torno do corpo, sob a forma de abluções. Seu pai não continuou estes cuidados particulares do corpo.

Os dois meses de separação, durante os quais ficou privado da presença de sua mãe, são uma repetição do primeiro trauma. 
Recupera um pouco da liquidez dada em compensação da que the faltou quando estava em estado fetal e também os cuidados corporais sob a forma de abluções bastante longas, massagens com cremes, que o pai não podia lhe dar, produzindo, a partir de seu próprio corpo, substâncias que desempenhavam o papel de páraexcitação.

Desejaríamos observar o quanto o momento da aprendizagem do controle esfincteriano pode despertar problemáticas ligadas ao nascimento, aos líquidos intra-uterinos e à ruptura da bolsa, no momento do parto.

O fato de ajudar a criança a mentalizar, a pôr em palavras o que causou o traumatismo permite-lhe desprender-se, progressivamente, do impacto paralisador, sobre a psique, do que vivenciou e a ajuda a ultrapassar o aspecto invasivo do trauma. Um contato físico mais estreito da parte dos pais, seguido de beijos, permitiu a Adriano sentir-se reunido e contido, não mais ameaçado de se dissolver. Cessou, então, ao cabo de um certo tempo, de investir nestas "brincadeiras".

A incompreensão do entorno pode, de fato, provocar um sentimento de abandono, de queda catastrófica na dificuldade, o que reforça as angústias de escoamento, a sensação de extrema vulnerabilidade e a impressão de uma ausência de continente.

A etapa da aprendizagem do controle esfincteriano reativa as angústias de saída do corpo. A criança, de fato, de ambos os sexos, como Freud demonstrou, engendra, fantasmaticamente, ao evacuar suas fezes. Esta vivência em torno do sólido e do líquido lembra, simbolicamente, sua própria experiência de nascimento, isto é, a passagem do líquido para o "seco". Tornar-se seco, oferecendo, definitivamente, as fezes, pode ser uma reevocação traumática do nascimento e do que o precedeu, se este "seco" foi vivenciado no meio intra-uterino.

\section{O CASO DE EMÍLIA}

Relataremos, igualmente, o caso de Emília, que nos permitirá abordar a despertar de angústias arcaicas ligadas à retenção e ao escoamento. Emília é uma criança de 2 anos e meio, que freqüenta a área de recreação há mais de um ano. Tímida, seu rosto expressa pouca emoção. Seus olhos estão, com freqüência, "arregalados", ela observa muito. Mais para passiva, Emília não fala quando está na área de recreação, não interpela os adultos. Do ponto de vista motor, é relativamente inibida no grupo e apresenta uma lentidão que 
fica mascarada, na maior parte do tempo, por sua imobilidade. $\mathrm{Na}$ sala, pega pouco os brinquedos, fica perto dos adultos, não vai ao encontro das crianças. Ao contrário, pára de se mexer quando elas correm ou fazem algazarra perto dela, como fazem as crianças quando começam a aprender a caminhar, de medo de se desequilibrar. No entanto, Emília sabe caminhar corretamente há vários meses.

Começamos um trabalho de solicitação e de encorajamento de Emília. A recreacionista dedica-lhe um pouco de tempo individual, utilizado para mostrar-lhe certos brinquedos. Ela começa a se interessar por uma outra criança com a qual se relaciona. É descrita por sua família como alguém que se expressa em casa, o que não é o caso na área de recreação.

Sua timidez é tal, que, quando uma pessoa não familiar chega, Emília a olha sem se mexer. Por outro lado, o fato de ser observada no contexto do trabalho da psicóloga a perturba e intriga ao mesmo tempo. Ela ouviu perguntas a seu respeito, e isto reforça sua inibição quando nos vê. É como se não ousasse fazer mais nada.

Sua família, pouco alertada até então, tenta, aos 2 anos e meio, ensinar-lhe a controlar os esfíncteres. Pais e avós se dedicam à tarefa, alternadamente, considerando o fracasso de Emília como preguiça. Uma atitude coercitiva se instala, consistindo em deixar Emília, durante muito tempo, no penico, embora ela nunca tenha solicitado o que quer que seja. Segundo os avós, que substituem, com freqüência, os pais, à noite, Emília não gosta de ficar suja. Além disso, de seu ponto de vista, já é tempo de ela ter controle esfincteriano, pois dentro de alguns meses irá para a escola.

$\mathrm{Na}$ área de recreação, é o conjunto do comportamento de retenção que nos interpela, já há bastante tempo: retenção nas comunicaçōes e nos movimentos. Emília nada solicita. Ela investe muito pouco o espaço, nada diz, não traz nenhum jogo, não apresenta nenhum brinquedo aos adultos. Se alguns progressos ocorreram após nosso trabalho de solicitação, observamos, com nitidez, que, a partir do momento em que sua família tenta ensinar-lhe o controle esfincteriano, Emília regride e fica cada vez pior. Mobiliza, desde então, toda sua energia para não se mexer. Torna-se imóvel e rígida, sobretudo no nível das pernas, e, quando é solicitada a avançar, mexe-as muito lentamente, como pedaços de pau. Isto faz pensar em uma criança que tem muita vontade de urinar, mas que, para se reter, não se mexe mais. Emília passa, desde então, os dias retendo-se, quase imóvel, não produzindo nenhuma emissão: nem urina, nem fezes, permanecendo a fralda sempre intacta.

Sua angústia é perceptível. Seu hiperdomínio dos esfíncteres, sua retenção dos líquidos e seu recurso de enrijecimento muscular, como tentativa de reforçar seu Ego-Pele (defesa tão bem descrita 
por E. Bick), fazem pensar nas angústias arcaicas de escoamento e de liquefação que F. Tustin descreveu tão bem.

O mutismo que demonstra na área de recreação pode ser compreendido como se se tratasse de guardar o máximo dentro de si. Além disso, ao não interpelar nenhum adulto e ao permanecer quase "paralisada no mesmo lugar", Emília mostra que ela se sente sozinha no que ela está vivenciando e que isto cria uma distância em relação ao outro.

A recreacionista solicita, então, uma entrevista com a mãe. Ela expõethe as dificuldades de Emília e the sugere que venha me ver. É assim que encontrei a mãe de Emília, na presença desta.

Considerando as defesas arcaicas utilizadas, orientamos as questões para os primeiros meses de vida de Emília. Aparecem elementos essenciais que sua mãe tinha deixado de lado. Estes comportam três temas que são reavivados pela aprendizagem do controle dos esfíncteres, o que explica a intensidade atual do mal-estar de Emília. Os três temas são: uma história de líquido, um líquido vital e tóxico ao mesmo tempo, uma história de "evacuação problemática" deste líquido com uma fortíssima retenção e a necessidade vital de um "controle".

De fato, nessa entrevista, a mãe de Emília conta que sua filha apresentou, no nascimento, uma hidrocefalia. Como o excesso de líquido cefalorraquidiano aumentava a pressão dentro do cérebro, a foice do cérebro (parte deste) corria o risco de escapar ao se deslocar e, 
mais precisamente, de "cair no buraco" occipital, segundo a expressão médica consagrada. Emília corria o risco de entrar em coma e morrer. As hidrocefalias desta natureza podem, também, provocar, de um ponto de vista médico, sintomas tais como desequilíbrios, lentidão, etc. Foi necessário colocar um dreno para evacuar este líquido.

Emília reencenou, no momento da aprendizagem do controle esfincteriano, o problema da retenção dos líquidos. Sem dúvida, sente-se incapaz de esfincterizar de maneira flexível. É como se, como com o dreno, ela corresse o risco de ser ameaçada de escoamento contínuo.

$O$ que parece importante, nesse caso, é deixar Emília reapropriar-se de seu corpo, de seus líquidos internos, de sua regulagem e explicarthe que a esfincterização é uma função, uma capacidade, que lhe pertence e que ela pode, sem risco, experimentar e dela se apropriar, contrariamente ao que se passou com ela quando bebê. Isto é, afastar-se da "atitude coercitiva" para não repetir a evacuação do líquido corporal imposto por outrem, funcionando a atitude coercitiva parental como uma repetição.

$O$ que parece essencial observar, neste caso, é a que ponto a aprendizagem do controle esfincteriano pode despertar angústias de morte ligadas aos problemas da regulagem dos líquidos internos.

Além do simbolismo mais "neurótico", é essencial, com uma criança como Emília, não esquecer o registro "mais arcaico", o das an- gústias de ressecamento e de escoamento. Encontramos, em seu caso, um comportamento que F. Tustin descreve em uma outra criança, que, ao enfrentar angústias de se derramar, reage cessando de fazer o que quer que seja.

No que diz respeito a Emília, pode-se dizer que, sem um trabalho de acompanhamento psíquico de suas angústias, é bastante difícil levá-la a se desprender desses líquidos e emissões com os quais está tão identificada.

\section{CONCLUSÃO}

Essas duas vinhetas clínicas ilustram a que ponto, para algumas crianças que apresentam dificuldades por ocasião da aprendizagem do controle esfincteriano, pode ser necessário voltar aos eventos que circundaram o nascimento, em um registro mais arcaico com o qual as crianças desta idade permanecem muito conectadas.

A abordagem das angústias precoces pode ser suficiente para produzir mudanças muito rápidas em relação à abordagem desta etapa pela criança. O fato de ajudar a criança a mentalizar, a colocar em palavras o que o traumatismo produziu permite-lhe desvencilhar-se, progressivamente, do impacto paralisador sobre a psique do que a criança vivenciou $e$ a ajuda a ultrapassar o aspecto invasivo do trauma. Isto the possibilita assimilar melhor as aprendizagens ulteriores. Assim, para Adriano, o fato de falar sobre seu nascimento, do 


\section{Dossiê}

que ele sofreu, e de solicitar aos pais que, regularmente, o pegassem no colo para fazer-lhe um carinho que permitisse que se centrasse novamente em um contato relacional estreito, permitiu a mudança de seu comportamento. Da noite para o dia, parou sua fascinação pelas toilettes das crianças e pôde começar a investir em outras brincadeiras.

Quanto a Emília, com a aproximação do reinício das aulas, um atendimento especializado foi instituído, fora do espaço da área de recreação. A entrevista com sua mãe permitiu ainda que a sua família encarasse e interpretasse de maneira mais apropriada a recusa diante do penico, em um contexto não mais de confronto, mas de acompanhamento e tranqüilização.

$A$ incompreensão do entorno pode, de fato, provocar um sentimento de "abandono" e de "queda catastrófica" na dificuldade, o que reforça as angústias de escoamento, a sensação de extrema vulnerabilidade e a impressão de uma ausência de continente.

É, de fato, primordial que a mãe e/ou o pai possam "sonhar" seu filho e suas dificuldades, no sentido que Bion o concebe, quer dizer, pôr sentido e palavras no que a criança vivencia.

Quando se trata de eventos precoces, que levaram a cuidados dolorosos ou a angústias de morte na mãe em relação à sobrevivência de seu bebê - que foi o caso de Emília -, o desenvolvimento "normal" da criança faz com que sua mãe se apresse em "esquecer" o que foi vivido como uma lembrança muito 
ruim. "Aconteceu... mas eu deixei para trás", dirá ela. Pode-se imaginar o quanto é difícil para uma mãe acompanhar e assistir a cuidados tão intrusivos e violentos, ao mesmo tempo que, com sua presença, os cauciona. Para os pais, assim que a criança fica "curada", o alívio se instala acompanhado pela impressão "de ter escapado desta", definitivamente.

Para a criança, a vivência dessa experiência será completamente diferente: não se trata de "escapar”, mas de ligar esta vivência à sua história, inscrevendo-a nela. É, portanto, todo um trabalho de ligação que deve ser efetuado, não de maneira definitiva, mas progressivamente, em função das etapas psíquicas que a criança vai ultrapassar e das zonas do ego corporal a que dizem respeito. A etapa da aprendizagem do controle esfincteriano desperta, mais particularmente, vivências intra-uterinas, a questão da ruptura da bolsa no parto e da passagem "para o seco", ao ar livre, assim como os problemas ligados às angústias de escoamento e aos líquidos internos.

A esse propósito, desejaríamos dar duas informações complementares, apoiando esta noção de risco de morte por escoamento e de risco de ressecamento. Estes dois dados provêm de um outro campo: o da medicina. Existe, de fato, por ocasião do desenvolvimento do feto, um risco de anomalia genética que tem efeitos sobre o desenvolvimento da caixa craniana e da pele circundante, o que pode, realmente, levar a um escoamento do cérebro atrás da cabeça, por falta de retenção. É interessante ligar as angústias arcaicas a estas etapas intra-uterinas.

Além disso, existe, igualmente, em medicina, uma síndrome que se chama "a síndrome seca", que pode aparecer, no envelhecimento, com freqüência após um choque afetivo (falecimento). Esta síndrome se manifesta pelo desaparecimento súbito das lágrimas, da saliva, etc., isto é, por um ressecamento concreto dos líquidos corporais. O que nos parece ilustrar estas duas patologias e as duas vinhetas clínicas relatadas neste artigo diz respeito à complexidade das vivências arcaicas e ao vestígio que elas deixam em qualquer idade da vida.

\section{REFERÊNCIAS BIBLIOGRÁFICAS}

Abraham, K. "La valorisation narcissique des excrétions dans le rêve et dans la névrose”, in Euvres complètes, T. II, pp. 72-75.

"Esquisse d'une histoire du développement de la libido fondée sur la psychanalyse des troubles mentaux", in Euvres complètes, T. II, pp. $170-226$ 


\section{Dossiê}

"Etudes psychanalytiques de la formation du caractère", in CEuvres complètes, T. II, pp. 227-245.

Freud, S. (1962). Trois essais sur la théorie de la sexualité. Paris: Gallimard.

(1973). La vie sexuelle, trad. coll. P.U.F, Paris, 4ème édition.

---- (1989). Nouvelles conférences d'introduction à la psychanalyse, trad. R. M. Zeitlin, Gallimard, Paris.

Haag, G. (1994). "Aux sources de la vie. Le langage préverbal et l'émergence des représentations du corps en situation psychanalytique individuelle ou groupale. avec des enfants autistes", in Dialogue, 123, ler trimestre, pp. 40-58.

Maldavsky, D. (1995). Apports théoriques à l'étude de la détresse précoce. La clinique de l'altération interne. Pulsion de dormir, pulsion de respirer, pulsion de guérir. Conférence donnée à l'Institut Claparède, Paris.

Tustin, F. (1989). Le trou noir de la psychée, Editions du Seuil, Paris.

Winnicott, D. W. (1975). "La crainte de l'effondrement", in Nouvelle Revue de Psychanalyse, 11 , pp. 35-44.

Recebido em 5/6/2001. 